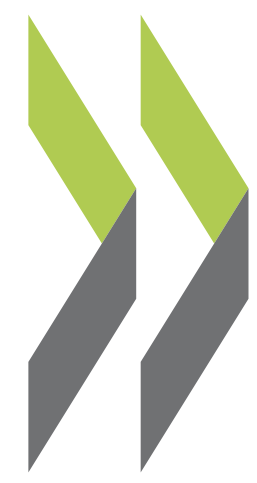

PEB Exchange, Programme on Educational Building 2003/08

\title{
Current Concerns for Austrian School Facilities
}




\section{CURRENT CONCERNS FOR AUSTRIAN SCHOOL FACILITIES}

The Austrian Institute for School and Sport Facilities (ÖISS) is responsible for current issues and problems related to the country's educational buildings. Four recent concerns of ÖISS's work are summarised here: schools as low energy buildings, electromagnetic fields and school buildings, chairs and tables for educational buildings, and school grounds - "learnscapes". Further items of ÖISS deal with lighting and acoustics and with buildings without barriers.

\section{Schools as low energy buildings}

Concepts for low energy buildings play an important role in recent Austrian architecture, and school buildings are no exception. A few low energy schools have been built in Austria, however the local conditions are different for each and their success depends largely on the ability and willingness of teachers and staff to handle and maintain the technical systems.

The concepts for low energy buildings entail compactness, high insulation, three-pane windows and glass panels, and ventilation systems. Once a certain degree of compactness and insulation are ensured, energy loss is mostly caused by window ventilation, so alternatives have to be considered. Poor air conditions due to $\mathrm{CO}_{2}$ pollution in highly occupied classrooms contribute to the problem.

ÖISS invited an experienced Austrian engineering office to research how school buildings can serve as low energy structures, taking into account the specific characteristics of and demands for educational facilities. The resulting study provides information on energy, comfort, heating, natural and artificial lighting, overheating in summertime and humidity.

An entire chapter is dedicated to the question of ventilation. Different systems such as partly automated window ventilation and centralised and decentralised controlled mechanical ventilation are compared with regard to $\mathrm{CO}_{2}$ pollution, heating and electricity requirements, and production and maintenance costs. As the success of technical systems depends on local handling and maintenance, ÖISS does not recommend a specific ventilation system but offers advice and examples of successful and unsuccessful test cases.

The study in German is available through ÖISS.

\section{Electromagnetic fields and school buildings}

Due to the use of multiple electronic devices in daily life, exposure to electromagnetic fields has increased significantly in the recent past. Moreover mobile phone transmitter poles are frequently situated on school buildings.

ÖISS invited the Austrian Research Centre (Seibersdorf Research) to study the exposure of electromagnetic fields on educational buildings and possible precautionary actions. The study, completed in 2002, gives information about safety levels of electromagnetic fields related to frequency, precautionary strategies, and possible steps to take in planning, constructing and maintaining educational buildings. This study is principally addressed to experts, but a summary for non-experts has also been written by an ÖISS working group. The summary explains, for example, that exposure to electromagnetic fields is much higher from direct contact with a mobile phone than from close proximity to a transmitter pole. Due to characteristics of transmission, the exposure in neighbouring buildings is often higher than in the very houses beneath poles. Still this item requires care in dealing with concerned parents. Measurements of exposure in comparison with safety levels can be helpful in dissipating worries.

The study and the summary (both in German) are available through ÖISS.

\section{Chairs and tables for educational buildings}

Presently a new European standard on "Furniture - Chairs and Tables for Educational Buildings" is being developed by CEN/CENELEC. ${ }^{1}$ However the current draft and the pre-standards, published in 2001, do not meet Austrian ergonomic standards for such furniture. The Austrian working group therefore decided to establish a complementary Austrian standard. ÖISS is involved in this process while at the same time writing its own guidelines, directed mainly toward users (principles, teachers, students and staff). While the European and the Austrian standards are addressed to furniture manufacturers, ergonomic conditions in schools are hindered by the lack of information for users. The ÖISS guidelines will inform users of ways to improve students' posture, movement, behaviour and development, such as:

- using ergonomic furniture;

- adapting the furniture to each individual based on periodical measurements of the students;

1. CEN is the European Committee for Standardization, and CENELEC, the European Committee for Electrotechnical Standardization. 
- using tabletops that adjust to different types of work and that incline for writing and reading positions;

- encouraging "dynamic seating positions" (sitting in different positions, standing, walking around) during class;

- offering physical activities before, between and after classes.

The ÖISS guidelines also present advantages and disadvantages of specific furniture such as adjustable and multi-size furniture.

The Austrian standard (ÖNORM A 1650) and the ÖISS guidelines will be completed in summer 2003.

\section{School grounds - "learnscapes"}

In the 2000, aware of the importance of outdoor activities in everyday school life, ÖISS founded a working group for initiatives in school grounds. Its members include planners (landscape architects and architects), psychologists, educationalists and civil servants. They offer information related to school grounds, organise events and support school projects through consultation and workshops. The working group has defined the following principles for the design and use of school grounds:

- The school grounds should provide areas for movement, sports, recreation and communication during leisure time.

- The grounds should be an integral part of school life and function as a setting for learning and other activities. This requirement refers to the principle of "learnscapes", which combines the idea of "learning by experience" with "landscape" as a practical hands-on teaching and learning area.

- Sustainability, gender and diversity mainstreaming, flexibility, ecology and multifunctionality should be guaranteed in all school ground settings.

- Participation of students, teachers, parents and staff should play an important part in the planning, realisation and maintenance process.

The working group has been offered the opportunity to test its methods and principles with a Viennese project, to evaluate the process and to work out general guidelines for school grounds. This pilot experiment is presently in progress and should provide valuable experience.

ÖISS would be interested to learn how other countries handle these or other subjects and invites similar organisations to share their ideas and experiences. Please contact.
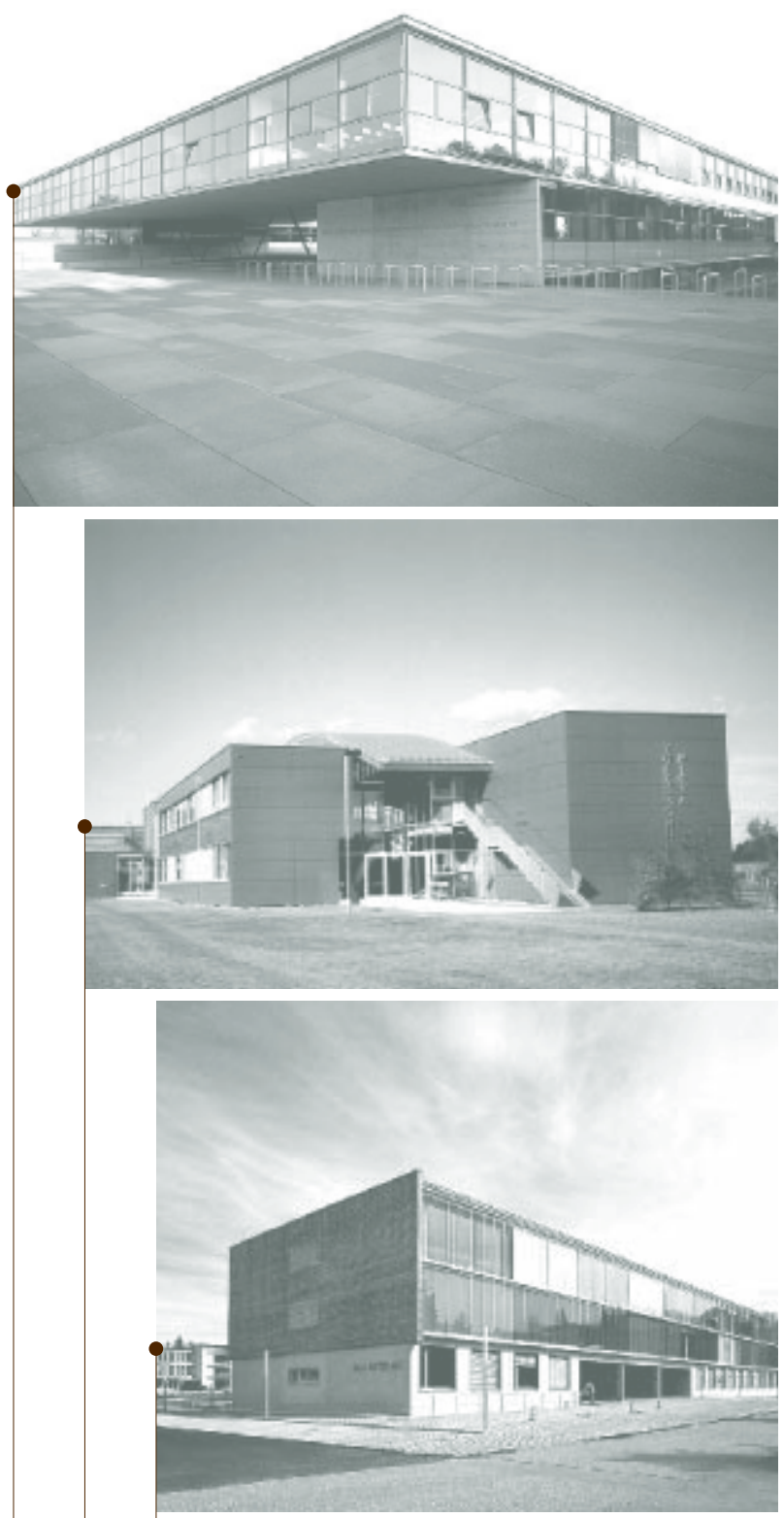

ÖKO-Hauptschule Strasswalchen, a lower secondary school in Salzburg, the second low energy school built in Austria, still needing a few modifications to work well for the users

Volksschule Pirka, a primary school in Steiermark, whose combination of prefabricated and wooden structures creates a warm environment

AHS Heustadelgasse, a secondary school opened in 2002 in Vienna, with outstanding, transparent architecture

\section{Karin Schwarz-Viechtbauer}

Österreichisches Institut für Schul- und Sportstättenbau (ÖISS)

Prinz-EugenStraße 12

\section{A - 1040 Vienna}

\section{Austria}

Tel: $004315058899 / 15$

Fax: 00431505889920

E-mail: schwarz@oeiss.org

www.oeiss.org 